\title{
Outcome of cervical spine surgery in patients with rheumatoid arthritis
} K M van Asselt, W F Lems, E B Bongartz, H L Hamburger, K W Drossaers-Bakker,
B A C Dijkmans, R M van Soesbergen

\begin{abstract}
Objectives-Cervical spine instability in patients with rheumatoid arthritis (RA) may lead to cervical myelopathy or occipital neuralgia, or both. Morbidity and mortality in patients with RA treated with cervical spine surgery during two years of follow up were evaluated.

Methods-Between 1992 and 199655 patients with RA underwent cervical spine surgery because of occipital neuralgia or cervical myelopathy, or both. Patients were classified according to the Ranawat criteria for pain and neurological assessment before operation and three months and two years postoperatively. For occipital neuralgia a successful operation was defined as complete relief of pain and for cervical myelopathy as neurological improvement.
\end{abstract}

Results-Occipital neuralgia was present in 17 patients, cervical myelopathy in 14 patients, and 24 had both. Surgical treatment in the patients with symptoms of occipital neuralgia who were still alive two years after surgery was successful in 18/29 $(62 \%)$. In the surviving patients with cervical myelopathy neurological improvement of at least one Ranawat class was seen in $16 / 24(67 \%)$. Postoperative mortality within six weeks was $3 / 51(6 \%)$. Within two years after the operation 14/51 $(27 \%)$ of the patients had died; in most patients the cause of death was not related to surgery. The highest mortality $(50 \%)$ was found in the group of six patients with quadriparesis and very poor functional capacity (Ranawat IIIB).

Conclusion-Cervical spine surgery in patients with RA performed because of occipital neuralgia or cervical myelopathy, or both, is successful in most patients who are alive two years after surgery. However, the mortality rate during these two years is relatively high, which seems to be largely related to the severity of the underlying disease and not to the surgery itself.

(Ann Rheum Dis 2001;60:448-452)

Neurology, Slotervaart

Hospital

H L Hamburger

Correspondence to:

Dr R M van Soesbergen,

Slotervaart Hospital,

Louwesweg 6, 1066 EC

Amsterdam

redre@slz.nl

Accepted 26 September 2000 known complication: it is estimated tha cervical spine is affected in $36-86 \%$ of patients with RA. ${ }^{2}$ Clinical symptoms and signs
Rheumatoid arthritis (RA) is a chronic systemic disease characterised by synovitis, which articular ligaments and destruction of jo depend on the location of the lesion(s) and the degree of instability.

The atlantoaxial joint is prone to luxation in three directions. Anterior luxation of the atlas is the most common type, lateral luxation occurs less frequently. Both types can cause entrapment of the $\mathrm{C} 2$ nerve root, which may lead to occipital neuralgia. The pain may be severe, often waking patients from their sleep. The third direction is vertical luxation of the odontoid process, which occurs with destruction of the atlanto-occipital and atlantoaxial joints. This type of luxation usually compresses the medulla oblongata. Luxation of the vertebrae at lower levels also appears (subaxial luxation). Compression of the brain stem may lead to symptoms like dysphagia, diplopia, facial numbness, but also drop attacks, vertigo, and even apnoeas. ${ }^{3}$ All types of cervical luxations can cause signs of spinal cord compression: long tract symptoms like uncontrolled jerks, muscular weakness, increased tendon reflexes, Babinski's sign, Lhermitte sign, and incontinence. ${ }^{4}$

The natural course of conservatively treated (that is, without surgery) rheumatoid patients with myelopathy is poor: in a recent report all conservatively treated patients were bedridden within three years after the onset of myelopathy, and after seven years all patients had died. ${ }^{5}$

In this study we evaluated the outcome after cervical spine surgery, measured by mortality and morbidity, in rheumatoid patients with occipital neuralgia with or without cervical myelopathy and in patients with cervical myelopathy only, during a follow up period of two years.

\section{Patients and methods}

We carried out a retrospective study of patients with RA, classified according to the American Rheumatism Association criteria, ${ }^{6}$ operated on in our hospital between 1992 and 1996 because of pathological processes of the cervical spine caused by RA. Patients with RA with cervical involvement requiring neck surgery are referred to our hospital from a large part of the Netherlands. Occipital neuralgia was defined as a severe distressing pain, caused by compression of the $\mathrm{C} 2$ nerve root, with radiation into the dermatome. Cervical myelopathy was defined as compression of the spinal cord at a cervical level leading to motor, sensory, and/or sphincter disorders. All patients were examined by the same neurologist (HLH) and were classified according to the Ranawat criteria for pain and neurological assessment (table 1) In all patients diagnosed as having occipital neuralgia or signs of spinal cord compression, or 
Table 1 Ranawat criteria for pain and neural assessment

Pain assessment Grade 0: None

Grade 1: Mild, intermittent, requiring only aspirin analgesia

Grade 2: Moderate; a cervical collar was needed

Grade 3: Severe; pain could not be relieved by either aspirin or collar

Neural assessment

Class I : No neural deficit

Class II: Subjective weakness with hyperreflexia and dysaesthesia

Class IIIA: Objective findings of paresis and long tract signs, but walking possible

Class IIIB: Quadriparesis with resultant inability to walk or to feed oneself

both, an $x$ ray examination and magnetic resonance imaging of the cervical spine were performed. Additionally, in some patients computed tomography scanning was considered necessary to assess bone destruction. The decision to operate was made when the clinical signs and symptoms were compatible with the imaging findings.

\section{HALO-TRACTION}

Halo-traction was applied before the operation, firstly, to diminish pain, secondly, to improve neurological symptoms, and, thirdly, to achieve the best possible preoperative correction at $x$ ray. The operation was planned when no further improvement could be achieved according to the abovementioned three criteria. During the halo-traction several supportive measures were taken, such as decubitus prevention by using a special bed, counselling, and intensive physiotherapy.

OPERATIONS

All patients were operated on by the same neurosurgeon (EBB). The operation consisted of ventral or dorsal fixations. Ventral fixations performed in the case of subaxial luxation at one level were plate fixations with bone inlay. Dorsal fixations can be divided into occipitalcervical (or occipital-thoracic) fixation using a plate-rod system and into cervical-dorsal fixations (C1-2, C1-3, or C1-4) with clamps. All operations are combined with autologous bone inlay.

Immobilisation in a halocuras followed surgery and lasted for three months, beginning on the fifth postoperative day.

FOLLOW UP

Three months and two years after the operation the patients were examined according to the Ranawat score for pain and neural assessment. $x$ Ray examinations were performed to verify the result of the operation three months postoperatively. Re-admissions to the hospital for cervical problems and for other reasons were registered.

Table 2 Characteristics of patient

\section{Results}

PATIENTS

Between 1992 and 1996 we examined 78 patients with RA with possible neck involvement. In 23 patients it was decided that an operation was not desirable because of a lack of indication for neck surgery (18 patients) or because of severe contraindications for operation (in five patients). Thus 55 patients were operated on.

The patient group comprised 46 women and nine men; all had erosive disease. Table 2 gives the age, disease duration, rheumatoid factor, presence or absence of nodules, and the use of corticosteroids. Seventeen patients had occipital neuralgia alone, 14 patients had signs of spinal cord compression, and both occipital neuralgia and myelopathy were found in 24 patients. No difference in the demographic factors and severity of the disease was found between the three groups (table 2). By definition, there was a difference in Ranawat scores between the three groups.

Fifty one patients underwent their first cervical operation in the period between 1992 and 1996. Four patients had their first cervical operation before 1992 .

\section{HALO-TRACTION}

Halo-traction was performed in 52 patients. In three patients with extensive pannus formation it was considered that halo-traction was not justified because the vertebrae were not malaligned. The mean duration of halotraction in 43 patients was 22.5 days (range 4-73); in nine patients the duration of halo-traction was not registered. In general, halo-traction was well tolerated. In three patients the duration of halo-traction was extremely long-38, 42, and 73 days, respectively - because of severe comorbidity or complications: pulmonary dysfunction, cricoarythenoid arthritis, and dens fracture.

\section{OPERATIONS}

Occipital-cervical (or occipital-thoracic) fixations were performed in 31 patients. Dorsal fixations from $\mathrm{C} 1$ to $\mathrm{C} 2, \mathrm{C} 3$, and $\mathrm{C} 4$, respectively were performed in 14 patients. We performed eight ventral fixations when there was subaxial luxations at one level. Two patients with subaxial luxations at several levels received a dorsal fixation.

CLINICAL OUTCOME

Table 3 shows the results of surgery. Only patients who underwent their first operation on

\begin{tabular}{llll}
\hline & $\begin{array}{l}\text { Occipital neuralgia } \\
(n=17)\end{array}$ & $\begin{array}{l}\text { Myelopathy } \\
(n=14)\end{array}$ & $\begin{array}{l}\text { Occipital neuralgia and } \\
\text { myelopathy }(n=24)\end{array}$ \\
\hline Median age (years, range) & $63(44-76)$ & $66(48-81)$ & $71(42-84)$ \\
Median duration of RA (years, range) & $17(2-56)$ & $17(5-53)$ & $16(3-39)$ \\
IgM rheumatoid factor positive (No (\%)) & $15(88)$ & $14(100)$ & $19(79)$ \\
Erosive (\%) & 100 & 100 & $7(29)$ \\
Nodules (No (\%)) & $7(41)$ & $6(43)$ & $14(58)$ \\
Corticosteroid use (No (\%)) & $9(53)$ & $7(50)$ & 1 \\
Ranawat class (neural assessment) at admission & & 0 & 8 \\
I & 17 & 2 & 13 \\
II & 0 & 8 & 2 \\
IIIA & 0 & 4 & \\
IIIB & 0 & & \\
\hline
\end{tabular}


Table 3 Results of the first operation on the cervical spine

\begin{tabular}{|c|c|c|c|c|c|c|c|}
\hline & \multirow[b]{2}{*}{ No pain } & \multirow[b]{2}{*}{ Pain } & \multicolumn{3}{|c|}{ Ranawat neural assessment ${ }^{\star}$} & \multirow[b]{2}{*}{ Total deaths } & \multirow{2}{*}{$\begin{array}{l}\text { Lost to } \\
\text { follow up }\end{array}$} \\
\hline & & & Improved & Same & Deteriorated & & \\
\hline \multicolumn{8}{|c|}{ Occipital neuralgia $(n=16)$} \\
\hline Preoperatively & 0 & 16 & & & & 0 & 0 \\
\hline After 3 months & 15 & 0 & & 15 & 0 & 1 & 0 \\
\hline After 2 years & 9 & 2 & & 9 & 2 & $5 \dagger$ & 0 \\
\hline \multicolumn{8}{|l|}{ Myelopathy $(n=12)$} \\
\hline Preoperatively & 12 & 0 & & & & 0 & 0 \\
\hline After 3 months & 10 & 0 & 6 & 4 & 0 & 2 & 0 \\
\hline After 2 years & 4 & 2 & 4 & 2 & 0 & $5 \dagger$ & 1 \\
\hline \multicolumn{8}{|c|}{$\begin{array}{l}\text { Both occipital neuralgia and } \\
\text { myelopathy }(n=23)\end{array}$} \\
\hline Preoperatively & 0 & 23 & & & & 0 & 0 \\
\hline After 3 months & 18 & 5 & 18 & 5 & 0 & 0 & 0 \\
\hline After 2 years & 9 & 9 & 12 & 5 & 1 & 4 & 1 \\
\hline
\end{tabular}

${ }^{\star}$ Changed at least one Ranawat class, compared with preoperative Ranawat class.

†Including the patients who died within three months.

the cervical spine are included in this table. Three months postoperatively $33 / 38$ (87\%) of the surviving patients with occipital neuralgia, whether or not combined with myelum compression, were free of pain, and after two years $18 / 29(62 \%)$ of the surviving patients were still free of pain. In the patients with occipital neuralgia alone the percentage of success was $100 \%$ and $82 \%$ after three months and two years, respectively. Patients with occipital neuralgia in combination with myelum compression had no pain in $78 \%$ and $50 \%$ after three months and two years respectively.

Postoperative neurological improvement after three months occurred in 24/33 (73\%) surviving patients with signs or symptoms of spinal cord compression, while after two years 16/24 (67\%) surviving patients were still in a better neurological class than before the operation.

During follow up, signs of spinal cord compression developed in two of 16 patients with (initially) occipital neuralgia alone. Two of the patients with myelopathy alone developed occipital neuralgia during the follow up period. There were no re-admissions. Only one patient with myelopathy at onset deteriorated by one Ranawat class after two years.

\section{RE-OPERATIONS}

Four patients underwent a re-operation. Their first operation was before 1992. Table 4 gives the previous operations and results of the last operation.

MORTALITY

Postoperative mortality, defined as death within six weeks after the operation, was $3 / 51$ $(6 \%)$. One patient died at home owing to an ischaemic stroke a few weeks after the operation. The second patient died suddenly for unknown reasons four days after discharge from hospital to a nursing home. The third patient died because of heart failure after a knee prosthesis operation, which took place during the same hospital admission.

After two years a total of 14 patients $(27 \%$ (95\% CI $22 \%$ to $33 \%)$ ) had died for various reasons (table 5).

The mean age at death was 64.9 years (range 44-76). Three patients (50\%) with Ranawat class IIIB at onset died within two years; for Ranawat classes IIIA, II, and I the numbers dying were $5(24 \%), 2(20 \%)$, and $4(22 \%)$, respectively.

The two year mortality rates (with $95 \% \mathrm{CI}$ ) of the patients with occipital neuralgia only, myelopathy only, and with both problems were $0.31(0.21$ to 0.41$), 0.42(0.28$ to 0.56$)$, and 0.17 (0.11 to 0.23 ), respectively.

HOSPITAL STAY AND DISCHARGE

The mean total, the preoperative, and the postoperative stay in hospital were 64 days (range 10-191), 31.8 days (range 1-74), and 32.4 days (range 0-115), respectively.

After the stay in hospital 38/53 (72\%) patients were discharged directly to their home, while $15 / 53(28 \%)$ patients were transferred to a rehabilitation centre or nursing home because they had no support at home (two patients died during the hospital stay).

\section{RE-ADMISSIONS}

In $40 / 55$ patients one or more admissions to the hospital were necessary within two years after the operation. The mean number of admissions for each patient (2.1) was higher in the group of patients with both occipital neuralgia and myelopathy than in those with occipital neuralgia alone (0.75) or myelopathy (0.79).

Two patients were re-admitted because of cervical spine involvement. The first patient had pain due to a broken implant, for which no re-exploration was necessary. The other patient developed sudden severe occipital pain during

Table 4 Results of re-operation

\begin{tabular}{|c|c|c|c|c|c|}
\hline & First operation and indication for first operation & $\begin{array}{l}\text { Ranawat class at onset, } \\
\text { indication for re-operation }\end{array}$ & $\begin{array}{l}\text { After } 3 \\
\text { months }\end{array}$ & $\begin{array}{l}\text { After } 2 \\
\text { years }\end{array}$ & Cause of death \\
\hline 1 & C4-5- spondylodese, myelopathy & I 2, myelopathy & I 0 & Deceased & $\begin{array}{l}\text { Aspiration of contrast fluid after failed } \\
\text { oesophagoscopy }\end{array}$ \\
\hline 2 & C6-7- spondylodese, myelopathy & I 2 , occipital neuralgia & I 0 & I 2 & \\
\hline 3 & C1-2- spondylodese, both occipital neuralgia and myelopathy & IIIA 0 , myelopathy & IIIA 0 & IIIA 1 & \\
\hline 4 & C1-2-spondylodese, C4-5-dese, occipital neuralgia and myelopathy & IIIB 0 , myelopathy & Deceased & - & Asystoly during operation \\
\hline
\end{tabular}


Table 5 Causes of death of patients operated on for the first time

\begin{tabular}{|c|c|c|}
\hline Period & $\begin{array}{l}\text { Ranawat class before } \\
\text { operation }\end{array}$ & Cause of death \\
\hline$<6$ Weeks & $\begin{array}{l}\text { I } \\
\text { IIIA } \\
\text { IIIB }\end{array}$ & $\begin{array}{l}\text { Stroke } \\
\text { Heart failure after knee operation } \\
\text { Sudden death, unknown reason }\end{array}$ \\
\hline$>6$ Weeks and $<2$ years & $\begin{array}{l}\text { I } \\
1 \times \mathrm{I}, 1 \times \mathrm{II} \\
\text { II } \\
\text { IIIA } \\
2 \times \mathrm{IIIA}, 1 \times \text { I } \\
1 \times \text { IIIA, } 1 \times \text { IIIB } \\
\text { IIIB }\end{array}$ & $\begin{array}{l}\text { Pulmonary disease } \\
\text { Sudden death, no necropsy } \\
\text { Infected spondylodesis } \\
\text { Unknown } \\
\text { Heart failure } \\
\text { Perioperatively during other operation } \\
\text { Stroke }\end{array}$ \\
\hline
\end{tabular}

Table 6 Review of results of surgery for myelopathy

\begin{tabular}{|c|c|c|c|c|}
\hline Author, year & $\begin{array}{l}\text { Number of } \\
\text { patients with } \\
\text { myelopathy }\end{array}$ & $\begin{array}{l}\text { \% With paresis } \\
\text { (IIIA and } B \text { ) }\end{array}$ & Mean age (years) & $\begin{array}{l}\text { Neural } \\
\text { improvement } \\
\text { postoperative (\%) }\end{array}$ \\
\hline Zoma, $1987^{14}$ & 32 & $\star$ & 60 & 60 \\
\hline Santavirta, $1988^{8}$ & 18 & 33 & 51 & 44 \\
\hline Peppelman, $1993^{15}$ & 110 & 53 & 61 & 87 \\
\hline Boden, $1993^{11}$ & 35 & 74 & 61 & 71 \\
\hline Casey, $1996^{10}$ & 134 & 100 & 63 & 51 \\
\hline Mori, $1998^{12}$ & 18 & 89 & 61 & 67 \\
\hline Eyres, $1998^{9}$ & 26 & 42 & 65 & $89 \dagger$ \\
\hline Plotz, $1998^{13}$ & 39 & 20 & 63 & 75 \\
\hline Present study & 35 & 71 & 65 & 73 \\
\hline
\end{tabular}

$\star$ Zoma did not use the Ranawat classification.

†Eyres used a modification of the Ranawat classification.

physical therapy suggesting a fracture. Fortunately, no fracture was diagnosed and the pain was relieved by a cervical collar. Orthopaedic interventions not related to the cervical spine were the most common reason for readmission - for example, nine operations of the wrist, eight hip replacements, and four knee replacements.

\section{Discussion}

In this study we observed the clinical effects of cervical spine surgery because of occipital neuralgia in patients with RA during two years of follow up. Reported data on percentages of patients in whom relief of pain was achieved by surgery are scarce, but, in general, operations were successful in most patients, varying from $78 \%$ to $92 \%{ }^{8}{ }^{9}$ However, in these studies only the direct postoperative effects are observed. These direct postoperative results are comparable with our data, according to which $100 \%$ of the surviving patients with occipital neuralgia only were free of pain three months postoperatively. Obviously, it is also important to observe the effects of (neck) surgery over a longer period of time. After two years, $82 \%$ of the surviving patients were free of pain, which is an important argument in favour of performing neck surgery in rheumatoid patients with occipital neuralgia alone, particularly as this distressing pain can be very severe, often awakening these patients from sleep.

On the other hand, in patients with occipital neuralgia in combination with myelum compression, only $78 \%$ and $50 \%$ had no pain any more (after three months and two years respectively), indicating that the pain relieving effect of surgery is not as evident in patients with more extensive disease. This may be related, among other factors, to progression of the underlying disease. Thus the abovementioned data suggest that particularly in patients with occipital neuralgia alone, surgery may be useful for relief of pain. Nevertheless, we realise that the numbers of patients in our study are relatively small and more data are required to confirm these observations.

Reported data on the results of cervical spine surgery are more extensive for patients with cervical myelopathy than for those with occipital neuralgia, which is probably because myelopathy has more clinical consequences (paresis!) than occipital neuralgia. We compared the data on postoperative results of cervical spine surgery in earlier studies (table $6)^{8-15}$ : the percentage of patients with neurological improvement varied from $44 \%$ to $89 \%$. Unfortunately, these results are not easy to compare because of differences in timing of the neurological examination, the preoperative Ranawat score, and the mean age of the patients. In most of these studies ${ }^{8-15}$ the results of surgery are evaluated directly postoperatively, whereas we observed effects three months and two years postoperatively.

In our patients, postoperative neurological improvement was observed in $73 \%$ and $67 \%$ of the surviving patients with cervical myelopathy (with or without occipital neuralgia), three months and two years after surgery.

Like other authors, we recommend an operation for patients with Ranawat classes IIIA and B because neural improvement is possible and may result in improved mobility.

To estimate the outcome of cervical spine surgery we analysed the results of the surviving patients only. Sensitivity analyses with a best (presume that all deceased patients would have had a good result) and a worst (presume that all deceased patients would have had no improvement after operation) case gives the intervals for the true value. For the 39 patients with signs of occipital neuralgia the results after two years must be somewhere between $46 \%$ and $72 \%$. For the 35 patients with signs of myelopathy this interval is $46-74 \%$.

In our opinion the causes of death were mostly not related to the surgery or due to aggregation of myelopathy. The true value is then more likely to be near the best case value.

Misclassification is common in retrospective studies. This should not be a major issue in this study because all patients were seen by the same neurologist.

It is not easy to interpret the effects of surgery in patients with serious neck problems due to RA. In fact, to avoid confounding by indication in this severely diseased group of patients, a randomised trial should be performed, comparing the long term results of surgery with that of the natural history. Obviously, this is unethical, because conservative treatment may lead to spinal cord compression, paresis, and even death. As mentioned before, Sunahara et al found that all the patients died in the first seven years after onset of myelopathy in conservatively treated patients, ${ }^{5}$ and all patients became bedridden within three years of conservative treatment. An indication for an operation was seen in these patients, but they refused this operation. 
Patients with serious cardiovascular morbidity were excluded.

Quality of life analysis should be performed to establish whether operating on these patients relieves pain and increases mobility.

In the future the positive effects of surgery (pain relief or neurological improvement, or both) have to be weighed against the disadvantages, of which the high mortality is the most important. Mortality rates in several studies are not comparable because of differences in age, duration of follow up, and the severity of the underlying disease. In other studies considering the effects of cervical spine surgery, mortality rates varied from $26 \%$ to $58 \% .^{10111216}$

One of the more intriguing questions is whether mortality is directly related to surgery or to other factors (which may be present only in a subgroup of patients). In our group of patients, three $(6 \%)$ died directly postoperatively, which may or may not be related to surgery, while $11(22 \%)$ other patients died during the later part of the two years of observation. This two year mortality rate is not dominated by surgery itself. Unfortunately, not all causes of death were known. The fact that mortality was largely increased (50\%) in the group of patients with Ranawat IIIB is an argument indicating that mortality is particularly related to the severity of the underlying disease. Many reports describe the risk ratio of RA to the general population. According to most of them the disease is associated with a shorter life span, with an excess of deaths due to cardiovascular disease and cerebrovascular causes. ${ }^{17-19}$ One hospital based study found no increased risk, but this was estimated in a group with a duration of disease of $8-13$ years. ${ }^{20}$ Patients with occipital neuralgia or myelopathy, or both, are the most serious cases. Comparing them with all patients with RA is not possible without taking into account the functional class, the number of drugs used, and comorbidity.

In summary, these data suggest that in patients with RA, cervical spine surgery because of occipital neuralgia or myelum compression, or both, might be useful because of pain relief and/or because of neurological improvement, which may improve quality of life. These positive effects have to be balanced against a probably acceptable perioperative risk of death. The high overall mortality is predominantly related to the severity of the underlying disease.
We are grateful to Dr Batchelor, radiologist, Dr D v Schaardenburg, rheumatologist, and Dr Y vd Schouw, epidemiologist, for reading the manuscript critically.

1 Samy Abdou M, Hlavin ML. Abnormalities of the craniovertebral junction in rheumatoid disease. Part I: Assessment. Contemporary Neurosurgery 1996;18:1-7.

2 Colon PW, Isdale IC, Rose BW. Rheumatoid arthritis of the cervical spine: an analysis of 333 cases. Ann Rheum Dis 1966;25:120.

3 Drossaers-Bakker KW, Hamburger HL, Bongartz EB, Dijkmans BAC, van Soesbergen RM. Sleep apnoea caused by rheumatoid arthritis. Br J Rheumatol 1998;37:88994.

4 Santavirta S, Kankaanpaa U, Sandelin J, Laasonen E, Konttinen YT, Slatis P. Evaluation of patients with rheumatoid cervical spine. Scand J Rheumatol 1987;16:9-16.

5 Sunahara N, Matsunaga S, Mori T, Ijiri K, Sakou T. Clinical course of conservatively managed rheumatoid arthritis patients with myelopathy. Spine 1997;22:2603-8.

6 Arnett FC, Edworthy SM, Bloch DA, McShane DJ, Fries JF, Cooper NS, et al. The American Rheumatism Association 1987 revised criteria for the classification of RA. Arthritis Rheum 1988;31:315-24.

7 Ranawat CS, O'Leary P, Pelluci P, Tsairis P, Marchisello P, Dort L. Cervical spine fusion in rheumatoid arthritis. J Bone Joint Surg Am 1979;61:1003-10.

8 Santavirta S, Slatis P, Kankaanpaa U, Sandelin J, Laasonen E. Treatment of the cervical spine in rheumatoid arthritis. J Bone Joint Surg Am 1988;80:658-66.

9 Eyres KS, Gray DH, Robertson P. Posterior surgical treatment for rheumatoid cervical spine. Br J Rheumatol 1998;37:756-9.

10 Casey ATH, Crockard HA, Bland JM, Stevens J, Moskovich $\mathrm{R}$, Ransford AO. Surgery on the rheumatoid cervical spine for the non-ambulant myelopathic patient; too much, too late? Lancet 1996;347:1004-7.

11 Boden SD, Dodge LD, Bohlman HH, Rechtine GR. Rheumatoid arthritis of the cervical spine; a long term analysis with predictors of paralysis and recovery. J Bone Joint Surg Am 1993;75:1282-97.

12 Mori T, Matsunaga S, Sunahara N, Sakou T. 3 to 11 year follow up of occipitocervical fusion for rheumatoid arthritis. Clin Orthop 1998;351:169-79.

13 Plotz GM, Schutz U, Grob D. Die okzipito zervikale Fusion bei Chronischer Polyarthritis. Z Rheumatol 1998;57:14758.

14 Zoma A, Sturrock RD, Fisher WD, Freeman PA, Hamblen DL. Surgical stabilisation of the rheumatoid cervical spine: a review of indications and results. J Bone Joint Surg Br 1987;69:8-12.

15 Peppelman WC, Kraus DR, Donaldson WF III, Agarwal A. Cervical spine surgery in rheumatoid arthritis: improvement of neurologic deficit after cervical spine fusion. Spine 1993;18:2375-9.

16 Santavirta S, Konttinen YT, Laasonen E, Honkanen V, Anitti-Poika I, Kauppi M. Ten-year result of operations for rheumatoid cervical spine disorders. J.Bone Joint Surg $\mathrm{Br}$ 1991;73:116-20.

17 Wolfe F, Mitchell DM, Sibley JT, Fries JF, Bloch DA, Williams CA, et al. The mortality of rheumatoid arthritis. Arthritis Rheum 1994;37:481-94.

18 Rasker JJ, Cosh JA. Cause and age at death in a prospective study of 100 patients with rheumatoid arthritis. Ann Rheum Dis 1981;40:115-20.

19 Reilly PA, Cosh JA, Maddison PJ, Rasker JJ, Silman AJ. Mortality and survival in rheumatoid arthritis: a 25 year prospective study of 100 patients. Ann Rheum Dis 1990;49:363-9.

20 Lindqvist E, Eberhardt K. Mortality in rheumatoid arthritis patients with disease onset in the 1980 s. Ann Rheum Dis 1999;58:11-14. 